\title{
Retraction Note to: Spatial Interaction and Network Structure Evolve- ment of Cities in Terms of China's Rail Passenger Flows
}

\author{
DAI Teqi ${ }^{1}$, JIN Fengjun ${ }^{2}$ \\ (1. School of Geography, Beijing Normal University, Beijing 100875, China; 2. Institute of Geographic Sciences and Natural Resources \\ Research, Chinese Academy of Sciences, Beijing 100101, China)
}

Citation: DAI Teqi, JIN Fengjun, 2022. Retraction Note to: Spatial Interaction and Network Structure Evolvement of Cities in Terms of China's Rail Passenger Flows. Chinese Geographical Science, 32(5): 932-932. https://doi.org/10.1007/s11769-020-1132-1

\section{Retraction Note: Chin Geogr Sci 2008 18(3): 206-213}

doi: 10.1007/s11769-008-0206-2

This article (Dai and Jin, 2008) has been retracted at the request of the authors. The work presented in this article was previously published in Chinese (Dai et al., 2005).

All authors agree to this retraction.

\section{References}

Dai Teqi, Jin Fengjun, 2008. Spatial interaction and network structure evolvement of cities in terms of China's rail passenger flows. Chinese Geographical Science, 18(3): 206-213. doi: 10.1007/s11769-008-0206-2

Dai Teqi, Jin Fengjun, Wang Jiaoer, 2005. Spatial interaction and network structure evolvement of cities in terms of China's railway passenger flow in 1990s. Progress in Geography, 24(2): 80-89. (in Chinese)

Online date: $2020-06-17$

Corresponding author: DAI Teqi. E-mail: daiteqi@gmail.com

(C) Science Press, Northeast Institute of Geography and Agroecology, CAS and Springer-Verlag GmbH Germany, part of Springer Nature 2022 